\title{
Specific Binding of Nile Red to Apomyoglobin
}

\author{
Salina A. Chowdhury and Manho Lim* \\ Department of Chemistry and Chemistry Institute of Functional Materials, Pusan National University, \\ Busan 609-735, Korea. *E-mail: mhlim@pusan.ac.kr \\ (Received July 19, 2011; Accepted August 29, 2011)
}

\begin{abstract}
Fluorescence correlation spectroscopy (FCS) is an emerging fluorescence technique used to study the dynamics of proteins on a millisecond to microsecond time scale at the single-molecule level. Solution pH-modulated protein conformational changes can be manifested by binding rate, fluorescence lifetime, and binding specificity of a probe molecule. The fluorescence lifetime of Nile red (NR) bound to apomyoglobin (apoMb) was measured to be $6 \pm 0.3 \mathrm{~ns}$, much longer than that in water solution $(2.9 \pm 0.2 \mathrm{~ns})$. As the unfolding population of apoMb increased by lowering $\mathrm{pH}$ of solution, the fraction for the longer lifetime of NR decreased with an increasing fraction for the shorter lifetime of NR in water. Unlike 1-anilino-8-naphthalene sulfonic acid, which has many lifetimes due to nonspecific binding to the unfolded apoMb, NR bound to apoMb possesses only a single lifetime. These results suggest that NR binds specifically to native apoMb and thus can be utilized to probe the folding/unfolding dynamics of apoMb using FCS.
\end{abstract}

Key words: Fluorescence correlation spectroscopy, Fluorescence lifetime, pH denaturation, Folding/unfolding dynamics

\section{INTRODUCTION}

To fully understand protein function requires every detail of protein dynamics in all ranges of time scale. ${ }^{1}$ Fluorescence correlation spectroscopy (FCS) has become the method of choice for investigating various molecular properties such as diffusion, ${ }^{2-8}$ conformational dynamics of proteins, ${ }^{9-11}$ and binding and reaction kinetics ${ }^{11-14}$ at the single-molecule level. This is all due to the advancement of a single molecule spectrometer using confocal fluorescence measurement. ${ }^{15,16}$ FCS is very sensitive technique to study events in the millisecond to microsecond time range. FCS can be used to study the folding/ unfolding dynamics of proteins occurring a few microseconds and milliseconds. ${ }^{17-19}$ The fluorescence signal arises from many possible sources responsible for changing the number of fluorophores in the detection volume; these sources include molecular diffusion, ${ }^{20}$ chemical reaction, ${ }^{20-22}$ intersystem crossing to a triplet state, ${ }^{23,24}$ and conformational motion that alters fluorescence properties. ${ }^{25,26}$

1-Anilino-8-naphthalene sulfonic acid (ANS) has been used as a probe molecule of macromolecules as it is strongly fluorescent when bound to a protein and weakly fluorescent in water. Recently, a series of studies ${ }^{27-32}$ have been carried out to investigate the interaction of ANS with a protein, even in a partially or fully unfolded state. These studies showed that ANS can nonspecifically bind to the unfolded apomyoglobin (apoMb) as well as the bound one. If a dye molecule can specifically bind to a folded or unfolded protein, and its fluorescence quantum yield dramatically depends on binding to the protein, the dye can be utilized in probing folding/unfolding dynamics of the protein. Nile red (NR) shows a dramatic change in fluorescence quantum yield when surrounded by nonpolar amino acid residues of proteins, but is very weakly fluorescent in a polar environment. ${ }^{33,34}$ Accordingly, Nile red is a valid reporter of the hydrophobic sites of proteins exposed to solution. ${ }^{35}$

We have investigated the binding specificity of NR to apoMb in various $\mathrm{pH}$ solutions to find that it binds only to the native apoMb; when it binds, its fluorescence lifetime is roughly doubled and its fluorescence intensity dramatically increased. This feature indicates that the binding site of $\mathrm{NR}$ to apoMb is very specific, making NR an ideal probe to study the folding/unfolding dynamics of the protein.

\section{MATERIALS AND METHODS}

\section{Fluorescence lifetime}

Fluorescence intensity fluctuates as the number of fluorophores in the confocal volume changes by chemical reaction. Thus, the dynamics of the chemical reaction can be studied by FCS if the fluctuation is affected by the chemical reaction. Free NR is a very weak fluorescent dye and apoMb is non-fluorescent in water, but NR strongly fluoresces when bound to apoMb. When NR binds to 
apoMb, it likely occupies the heme cavity where the heme is located in the native $\mathrm{Mb}$. Since apoMb is much larger than NR, the diffusion coefficient of NR-bound apoMb (apoMb-NR) is nearly the same as apoMb alone. Nonetheless, apoMb unfolds as the solution becomes acidic, and the fluorescence intensity shows a cut off, as NR cannot bind the protein. From this fluorescence fluctuation we could calculate the diffusion coefficient of NR. The lifetime of free and bound NR, and the population of apoMb-NR, were also obtained, which showed that bound NR becomes free upon increasing the acidity of the sample.

\section{Experimental setup}

All experimentation was carried out using a homebuilt stage-scanning single molecule spectrometer described in our previous work. ${ }^{36}$ Briefly, it consisted of an inverted microscope equipped with an $x-y$ piezo actuator with a digital piezo controller, a picosecond diode laser coupled with an single-mode optical fiber, a single photon avalanche diode (SPAD), time-correlated single-photon counting (TCSPC) electronics, and a few optical components. The diode laser ran at $50 \mathrm{MHz}$, with a pulse width of ca. $60 \mathrm{ps}$ at a wavelength of $470 \mathrm{~nm}$ with $100-\mu \mathrm{W}$ laser power. A dichroic mirror and bandpass filters were used to separate the fluorescence from excitation, and a water immersion objective (60×, NA=1.2) was used to focus the excitation beam into the sample and recollect the fluorescence. The collected fluorescence was focused onto a SPAD. The TCSPC electronics were operated in the time-tagged timeresolved mode, which enabled recording of the arrival time of every detected photon with a temporal resolution in the nanosecond range, and its arrival time with respect to the last laser pulse with a picosecond timing resolution. All measurements and data analysis were performed using the SymPhoTime v.5.1.3 software (PicoQuant). The instrument was calibrated by measuring the diffusion coefficient of Rh123 in water.

The sample holder consisted of a cover glass (Corning, no. $1^{1 / 2}, 25 \mathrm{~mm}$ sq, thickness $0.17 \mathrm{~mm}$ ) and a glass culture cylinder (Bioptechs, $14 \mathrm{~mm} \times 5 \mathrm{~mm}$ ). Since background photons can easily outnumber photons from a single molecule, extreme care was taken to minimize any kind of contamination from solvent water, pipette tips, vials, cover slips, and cylinders any that could be a source of background photons. Cleaning procedures of sample holders were described in our previous work. ${ }^{36}$ Briefly, Sample holders were soaked, sonicated, and washed out alternately by a saturated $\mathrm{NaOH}$ solution, deionized water, concentrate $\mathrm{H}_{2} \mathrm{SO}_{4}$, and deionized water. This was followed by drying with a flow of nitrogen gas and storage in a UV oven overnight. If any potential background sources remained, the UV ray exposure would decompose large organic molecules that might emit background fluorescence.

Detection volume, estimated from the free diffusion of Rh123 in the deep solution $10 \mu \mathrm{m}$ from the surface and with an observed diffusion time of $41 \mu \mathrm{s}$, was calculated to be $\approx 0.65 \mu \mathrm{m}^{3}$, resulting in less than one molecule in the confocal volume for a $1 \mathrm{nM}$ solution. The focused beam size was confirmed by an independent measurement that scanned an image of a dye-coated bead (45-nm diameter). Fluorescence emissions of free and bound NR were measured using a fluorescence spectrophotometer (Hitachi, model: 250-0007).

\section{Sample preparation}

Horse skeletal muscle apoMb and NR were purchased from Sigma-Aldrich. At the desired pH, 0.1 M of buffer solution was made using the following acid/base pairs: $\mathrm{KH}_{2} \mathrm{PO}_{4} / \mathrm{K}_{2} \mathrm{HPO}_{4}$ for $\mathrm{pH}$ 7.4-6.0, $\mathrm{CH}_{3} \mathrm{CO}_{2} \mathrm{H} / \mathrm{KCH}_{3} \mathrm{CO}_{2}$ for $\mathrm{pH}$ 5.5-3.5, and $\mathrm{H}_{3} \mathrm{PO}_{4} / \mathrm{KH}_{2} \mathrm{PO}_{4}$ for $\mathrm{pH}$ 3.0-1.6.

Since NR does not dissolve directly in water, first, a 40 $\mathrm{mM}$ stock solution was prepared in $\mathrm{CHCl}_{3}$. The stock solution was diluted to the required concentration in deionized water using a sonicator at a 1000:1 portion of water and $\mathrm{CHCl}_{3}$. The $\mathrm{NR}$ in the aqueous solution was not stable and gradually deposited onto the bottom and surface of vial over time. To avoid deposition of the dye, the solution was mixed by sonication prior to making the sample each time; a freshly made NR solution was always used.

Table 1. Lifetime of NR under various acidic conditions in the presence and absence of apoMb. It was fitted by monoexponential or biexponential functions. The percent fraction of apoMb-NR in different solution $\mathrm{pH}$ is also shown. The lifetime of NR in ethanol and methanol are taken from the reference 39

\begin{tabular}{lccccccccc}
\hline & $\mathrm{pH}$ & 7.4 & 4.25 & 4.0 & 3.75 & 3.5 & 1.6 & EtOH & $\mathrm{MeOH}$ \\
\hline Parameters & & & & & & & & \\
\hline Absence of ApoMb & Free NR, ns & 2.9 & 2.8 & 2.8 & 2.7 & 3.0 & 2.9 & 3.65 & 2.8 \\
\hline \multirow{2}{*}{ Presence of ApoMb } & Free NR, ns & 2.9 & 2.7 & 2.8 & 2.9 & 2.9 & 3.1 & & \\
& ApoMb-NR, ns & 5.7 & 5.8 & 6.0 & 6.0 & 6.2 & & \\
& \% Fraction apoMb-NR & 49 & 32 & 28 & 23 & 20 & 0 & & \\
\hline
\end{tabular}


The sample $(500 \mu \mathrm{L})$ was prepared for each $\mathrm{pH}$ with $480 \mu \mathrm{L}$ buffer, $10 \mu \mathrm{L}$ apoMb of $260 \mu \mathrm{M}$, and $10 \mu \mathrm{L} \mathrm{NR}$ at a concentration of $25 \mu \mathrm{M}$. Finally, a $400-\mu \mathrm{L}$ sample solution was taken into sample holder for the experiments. The final concentration of apoMb in the sample was 5.2 $\mu \mathrm{M}$, and the concentration of NR was $0.5 \mu \mathrm{M}$. Data were collected for $600 \mathrm{~s}$ and three scans were taken for each sample. The confocal volume was placed deep into the solution, $20 \mu \mathrm{m}$ away from the surface to avoid surface influence in measurements. ${ }^{36}$ Whereas the fluorescence lifetime decay of the NR in water (free NR) was fitted by a single exponential, that in the presence of apoMb was fitted by a double exponential since there exist both apoMbNR and free NR in the protein solution. Table 1 summarizes the average values of lifetime and percent concentration for three independent measurements.

\section{RESULTS AND DISCUSSION}

A hydrophobic dye such as ANS binds to the heme pocket of apoMb, which is empty and relatively solvent exposed. ${ }^{37}$ ANS has been chosen as the probe dye to observe the structural fluctuations of apoMb by FCS, and revealed that the binding site of the dye is the hydrophobic heme pocket. ${ }^{1,38}$ Those studies showed that an additional binding site arises in apoMb for ANS at a lower $\mathrm{pH}$, and the conformations of apoMb becomes flexible enough to bind ANS non-specifically. That is why ANS is an unsuitable probe to study the folding/unfolding dynamics of apoMb. NR is very weakly fluorescent in aqueous solution whereas it strongly fluoresces in a hydrophobic environment, which makes it a good reporter of surroundings. First, we confirmed the binding of NR to the apoMb by examining the fluorescent intensity of NR alone in buffer and with mixing apoMb at pH 7.4 (Fig. 1). The fluorescence intensity increases dramatically and its peak position shows a blue shift, as apoMb is present. As mentioned above, when the environment of NR becomes hydrophobic from hydrophilic, the peak position of the fluorescence of lifetime is known to shift to blue with increasing intensity. ${ }^{35}$ The change in fluorescence intensity and the blue shift of the peak position confirm the binding of NR to apoMb. ${ }^{35}$

We also measured the diffusion coefficient of free NR using FCS and found the diffusion coefficients to be 490 $\mu \mathrm{m}^{2} / \mathrm{s}$ at $\mathrm{pH} 7.4$ and $250 \mu \mathrm{m}^{2} / \mathrm{s}$ at $\mathrm{pH} 1.6$. The diffusion coefficient of NR bound to the apoMb was measured at 87 $\mu \mathrm{m}^{2} / \mathrm{s}$ in a buffer of $\mathrm{pH} 7.4$, but $260 \mu \mathrm{m}^{2} / \mathrm{s}$ at $\mathrm{pH} 1.6$, considering only diffusion of the molecules through the con-

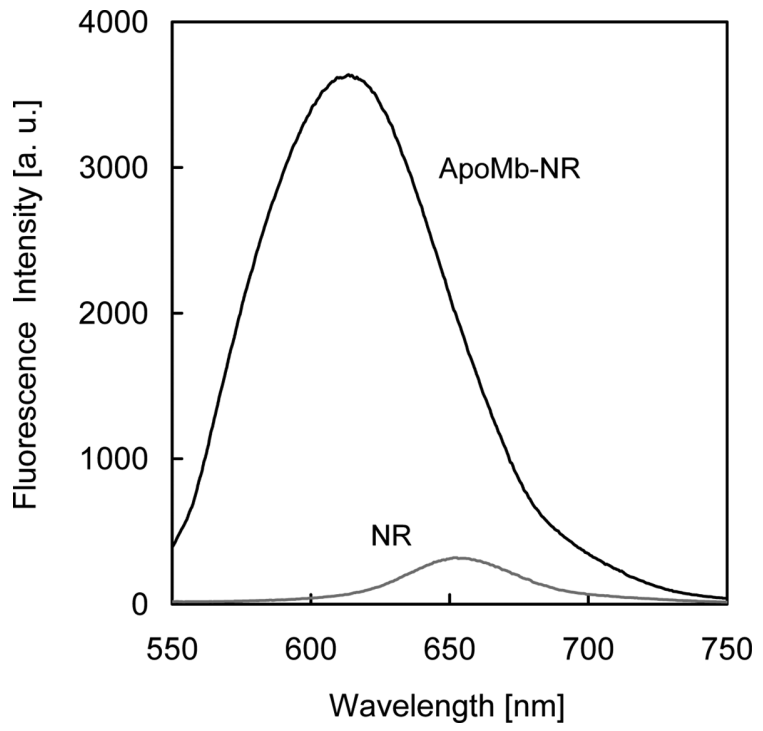

Fig. 1. Fluorescence intensity of NR in water (gray line) and bound to apoMb in water solution (black line) at $\mathrm{pH}$ 7.4. Fluorescence intensity of NR increases dramatically and shifts blue when bound to apoMb (apoMb-NR).

focal volume. Diffusion coefficient of free NR at $\mathrm{pH} 1.6$ is nearly the same to that of the dye in the presence of apoMb, suggesting that there is no apoMb-NR at $\mathrm{pH}$ 1.6. The decrease in the diffusion coefficient in solution at $\mathrm{pH}$ 7.4 indicates that the small dye molecule binds to the large apoMb molecule. In stronger acidic solutions, the apoMb becomes completely unfolded, and the heme cavity is no longer available to bind the dye, implying that NR binds specifically to the heme pocket of the native apoMb. Diffusion of NR at pH 1.6 is about two times slower than $\mathrm{pH}$ 7.4. Slowing of the free $\mathrm{NR}$ at $\mathrm{pH} 1.6$ may arise from stronger solvation of the dye in the acidic solution.

Fluorescence intensity decays of NR are shown in Fig. 2. In $\mathrm{pH} 7.4$, the fluorescence intensity decays faster in apoMb-free solution and much slower when apoMb is added. As the acidity of the solution increases, the fluorescence decay becomes faster. The fluorescence decay of the free NR was well described by single exponential function and the decay in the presence of apoMb became biexponential. The fitted fluorescence lifetimes are summarized in Table 1. The fluorescence lifetimes of both free and bound NR are nearly independent of the acidity of the solution. Free NR has a shorter lifetime of $2.9 \pm 0.2 \mathrm{~ns}$, while apoMb-NR has a longer lifetime of $6.0 \pm 0.3 \mathrm{~ns}$. The lifetime for the free NR is similar to that in the other polar solutions; the lifetime of NR in methanol and ethanol are $2.8 \mathrm{~ns}$ and 3.65 ns, respectively. ${ }^{39}$ As the acidity of the solution increases, the fluorescence decays with a less contribution from the 


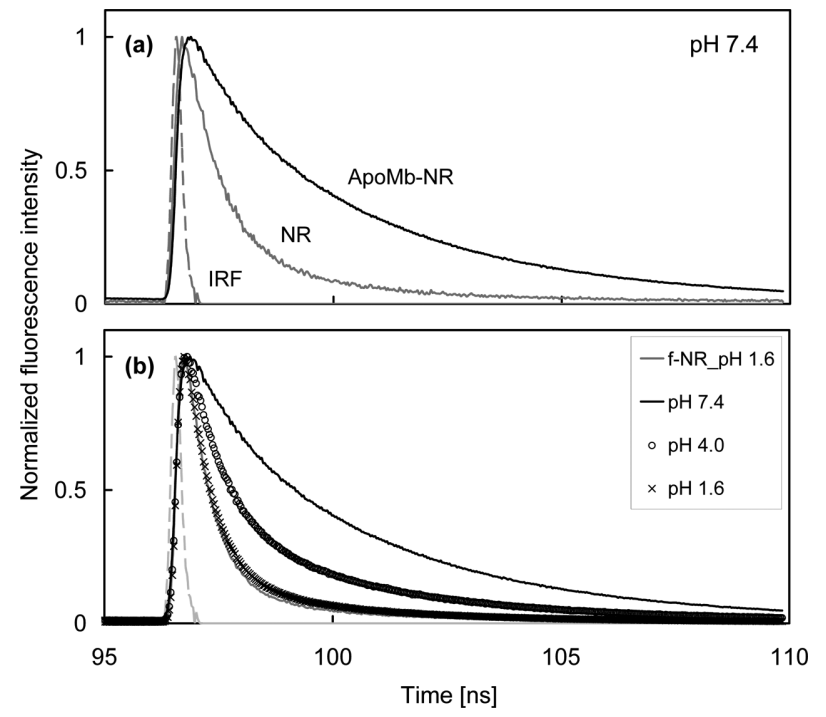

Fig. 2. Fluorescence decay of NR under various conditions. (a) Fluorescence decay of NR in the absence (gray solid line) and presence (black solid line) of apoMb in $\mathrm{pH} 7.4$ buffer at room temperature. (b) Fluorescence decay of NR in the presence of $\mathrm{apoMb}$ at various $\mathrm{pHs}$. The decay becomes faster as the acidity of the solution increases. The lifetime of $\mathrm{NR}$ at $\mathrm{pH} 1.6$ is the same in both the absence and presence of apoMb. Instrument response time (IRF) is also shown for comparison (dotted line).

apoMb-NR (see Table 1). At $\mathrm{pH}$ 1.6, the decays are virtually identical in both the presence and absence of apoMb, indicating that indeed there is no NR bound to the apoMb in a solution of $\mathrm{pH}$ 1.6. Clearly there are no binding sites available for NR binding in apoMb under highly acidic conditions since every apoMb exists in the unfolded state. The heme cavity of apoMb is unavailable in the unfolded state of apoMb in strongly acidic solutions, confirming that NR binds to apoMb specifically. If it binds non-specifically, either a new complex with a different lifetime is generated or the concentration of dye bound to apoMb remains unaffected. $\mathrm{ApoMb}$ has a specific binding site for NR, wherein the heme cavity is destroyed as the protein unfolds. This property makes NR as an ideal probe molecule to study folding/unfolding dynamics of apoMb.

The lifetime histogram of free NR in buffer is also calculated, as well as in room-temperature solutions in the presence of apoMb at various pHs (Fig. 3). In the case of ANS binding to apoMb, several additional lifetimes with a broad distribution are observed in the histogram of lower $\mathrm{pH}$ solutions. The additional lifetimes were suggested to arise from additional binding sites in the flexible unfolded protein in a low $\mathrm{pH}$ solution. ${ }^{1}$ Our experimental results for NR do not show any additional peaks at a lower $\mathrm{pH}$,

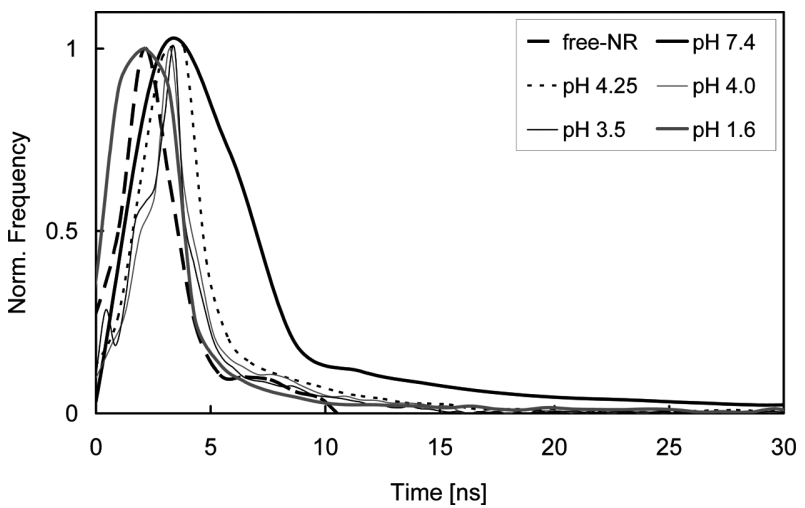

Fig. 3. Histogram for fluorescence lifetime of NR at room temperature in the presence of apoMb at various $\mathrm{pHs}$. Normalized frequency in the $y$-axis represents the normalized occurrence by the maximum occurrences in the histogram.

ensuring that no additional binding sites developed at lower $\mathrm{pH}$. It appears that there is an additional peak in the population near $7 \mathrm{~ns}$ when NR is in water without apoMb and in apoMb solution at $\mathrm{pH} 4$. We do not know the exact origin for this additional population. However, considering no systematic behavior in the appearance of the small peak and the negligible magnitude of the population (less than 5\%), the small peak cannot arise from additional binding site(s). With the increasing acidic nature of the sample, the peak becomes narrower, implying that the binding site of the NR to apoMb becomes more specific. The binding site of NR in apoMb is specific, making NR a suitable probe to study apoMb folding/unfolding.

\section{CONCLUSION}

Fluorescence emission shows NR as a probe dye similar ANS, binding to the heme pocket of apoMb. The binding affinity of NR is very sensitive to apoMb folding/ unfolding. The maximum fluorescence intensity is obtained while the protein remains in native state and less in the unfolded state. Fluorescence lifetime measurements, as well as diffusion coefficients of NR, ensure that NR binds to the apoMb specifically. As apoMb becomes unfolded with increasing solution acidity, the concentration of apoMb-NR decreases and the free NR increases. In very strong acidic solutions, there remains no apoMb-NR in the solution as all the proteins become unfolded. Unlike ANS, NR only binds in the heme cavity of the native apoMb specifically and thus, it can be an appropriate probe molecule to study the folding/unfolding dynamics of the protein. 
Acknowledgement. This research was supported by for two years by Pusan National University Research Grant.

\section{REFERENCES}

1. Bismuto, E.; Gratton, E.; Lamb, D. C. Biophys. J. 2001, 81,3510 .

2. Korlach, J.; Schwille, P.; Webb, W. W.; Feigenson, G. W. Proc. Natl. Acad. Sci. USA 1999, 96, 8461.

3. Yoshida, N.; Kinjo, M.; Tamura, M. Biochem. Biophys. Res. Comm. 2001, 280, 312.

4. Lead, J. R.; Wilkinson, K. J.; Starchev, K.; Canonica, S.; Buffle, J. Environ. Sci. Technol. 2000, 34, 1365.

5. Mahurin, S. M.; Dai, S.; Barnes, M. D. J. Phys. Chem. B 2003, 107, 13336.

6. Benda, A.; Benes, M.; Marecek, V.; Lhotsky, A.; Hermens, W. T.; Hof, M. Langmuir 2003, 19, 4120.

7. Guo, L.; Chowdhury, P.; Fang, J.; Gai, F. J. Phys. Chem. B 2007, 111, 14244.

8. Dertinger, T.; Pacheco, V.; Hocht, I. V. D.; Hartmann, R.; Gregor, I.; Enderlein, J. Chem. Phys. Chem. 2007, 8, 433.

9. Widengren, J.; Schwille, P. J. Phys. Chem. A 2000, 104, 6416.

10. Mei, E.; Tang, J.; Vanderkooi, J. M.; Hochstrasser, R. M. J. Am. Chem. Soc. 2003, 125, 2730.

11. Xiao, Y.; Buschmann, V.; Weston, K. D. Anal. Chem. 2005, $77,36$.

12. Xie, X. S.; Choi, P. J.; Li, G.-W.; Lee, N. K.; Lia, G. Annu. Rev. Biophys. 2008, 37, 417.

13. Min, W.; English, B. P.; Luo, G.; Cherayil, B. J.; Kou, S. C.; Xie, X. S. Acc. Chem. Res. 2005, 38, 923.

14. Eggeling, C.; Volkmer, A.; Seidel, C. A. M. Chem. Phys. Chem. 2005, 6, 791.

15. Rigler, R.; Widengren, J. Bioscience 1990, 3, 180.

16. Enderlein, J.; Gregor, I.; Patra, D.; Dertinger, T.; Kaupp, U. B. Chem. Phys. Chem. 2005, 6, 2324.

17. Clarke, D. T.; Doig, A. J.; Stapley, B. J.; Jones, G. R. Proc. Natl. Acad. Sci. USA 1999, 96, 7232.

18. Farazi, T. A.; Manchester, J. K.; Gordon, J. I. Biochemistry 2000, 39, 15807.
19. Holtzer, M. E.; Bretthorst, G. L.; d'Avignon, D. A.; Angeletti, R. H.; Mints, L.; Holtzer, A. Biophys. J. 2001, 80, 939.

20. Magde, D.; Elson, E. L.; Webb, W. W. Biopolymers 1974, $13,29$.

21. Lamb, D. C.; Schenk, A.; Rocker, C.; Scalfi-Happ, C.; Nienhaus, G. U. Biophys. J. 2000, 79, 1129.

22. Magde, D.; Elson, E.; Webb, W. W. Phys. Rev. Lett. 1972, 29, 705 .

23. Widengren, J.; Mets, U.; Rigler, R. J. Phys. Chem. 1995, 99, 13368.

24. Widengren, J.; Rigler, R.; Mets, U. J. Fluores. 1994, 4, 255.

25. Bonnet, G.; Krichevsky, O.; Libchaber, A. Proc. Natl. Acad. Sci. USA 1998, 95, 8602.

26. Haupts, U.; Maiti, S.; Schwille, P.; Webb, W. W. Proc. Natl. Acad. Sci. USA 1998, 95, 13573.

27. Demarest, S. J.; Horng, J. C.; Raleigh, D. P. Proteins 2001, 42, 237.

28. Li, Y.; Jing, G. J. Biochem. (Tokyo) 2000, 128, 739.

29. Muzammil, S.; Kumar, Y.; Tayyab, S. Eur. J. Biochem. 1999, 266, 26.

30. Ali, V.; Prakash, K.; Kulkarni, S.; Ahmed, A.; Madhusudan, K. P.; Bhakuni, V. Biochemistry 1999, 38, 13635.

31. Bedell, J. L.; McCrary, B. S.; Edmondson, S. P.; Shriver, J. W. Prot. Sci. 2000, 9, 1878.

32. Bhattacharyya, A.; Mandal, A. K.; Banerjee, R.; Roy, S. Biophys. Chem. 2000, 87, 201.

33. Dutta, A. K.; Kamada, K.; Ohta, K. J. Photochem. Photobiol. A 1996, 93, 57.

34. Ghoneim, N. Spectrochim. Acta A Mol. Biomol. Spectrosc. 2000, 56, 1003.

35. Sackett, D. L.; Wolff, J. Anal. Biochem. 1987, 167, 228.

36. Chowdhury, S. A.; Lim, M. Bull. Korean. Chem. Soc. 2011, 32, 583.

37. Cocco, M. J.; Lecomte, J. T. J. Protein Science 1994, 3, 267.

38. Polverini, E.; Cugini, G.; Annoni, F.; Abbruzzetti, S.; Viappiani, C.; Gensch, T. Biochemistry 2006, 45, 5111.

39. Cser, A.; Nagy, K.; Biczok, L. Chem. Phys. Lett. 2002, $360,473$. 